\title{
Moderately decreased maternal dietary energy intake during pregnancy reduces fetal skeletal muscle mitochondrial biogenesis in the pigs
}

Tiande Zou, Bing Yu, Jie Yu, Xiangbing Mao, Ping Zheng, Jun He, Zhiqing Huang, Yue Liu and Daiwen Chen*

\begin{abstract}
Background: Mitochondria are of major importance in oocyte and early embryo, playing a key role in maintaining energy homeostasis. Epidemiological findings indicate that maternal undernutrition-induced mitochondrial dysfunction during pregnancy is associated with the development of metabolic disorders in offspring. Here, we investigated the effects of moderately decreased maternal energy intake during pregnancy on skeletal muscle mitochondrial biogenesis in fetal offspring with pig as a model.

Methods: Pregnant Meishan sows were allocated to a standard-energy (SE) intake group as recommended by the National Research Council (NRC; 2012) and a low-energy (LE) intake group. Fetal umbilical vein serum and longissimus muscle samples were collected for further analysis on day 90 of pregnancy.

Results: Sow and fetal weights and the concentrations of serum growth hormone $(\mathrm{GH})$ and glucose were reduced in LE group. Maternal LE diet decreased the messenger RNA (mRNA) expression of genes involved in mitochondrial biogenesis and function such as peroxisome proliferator-activated receptor gamma coactivator 1a (PPARGC1A), nuclear respiratory factor 1 (NRF1), mitochondrial transcription factor $A$ (TFAM), $\beta$ subunit of mitochondrial $\mathrm{H}^{+}$-ATP synthase (ATB5B), sirtuin 1 (Sirt1), and citrate synthase (CS). The protein expression of PPARGC1A and Sirt1, intracellular $\mathrm{NAD}^{+}$-to-NADH ratio, and CS activity was reduced in LE group, and accordingly, mitochondrial DNA (mtDNA) content was decreased. Moreover, copper/zinc superoxide dismutase (CuZn-SOD) expression at both mRNA and protein levels and SOD and catalase (CAT) activities were reduced in LE group as well.

Conclusions: The observed decrease in muscle mitochondrial biogenesis and antioxidant defense capacity suggests that moderately decreased maternal energy intake during pregnancy impairs mitochondrial function in fetal pigs.
\end{abstract}

Keywords: Maternal energy intake, Skeletal muscle, Mitochondrial biogenesis, Oxidative stress, Fetal pig

\section{Background}

Obesity, characterized by an imbalance between energy intake and expenditure, is increasing at an alarming rate in most parts of the world. In particular, human epidemiological and animal experimental studies have demonstrated that hormonal, metabolic, and nutritional disturbances at crucial prenatal time periods may also

\footnotetext{
* Correspondence: dwchen@sicau.edu.cn

Key Laboratory for Animal Disease-Resistant Nutrition of the Ministry of

Education of China, Animal Nutrition Institute, Sichuan Agricultural University, Cheng du, China
}

determine the predisposition to deleterious health (1) this process are still unclear.

Mitochondria are of major importance in oocyte and early embryo, playing a key role in maintaining energy homeostasis [26, 40]. Deregulation of energy homeostasis is a common underlying characteristic of metabolic 
syndrome, and many studies have demonstrated that prenatal maternal undernutrition programs offspring mitochondrial function in various tissues of different animal models, such as the pancreatic islet [41] and kidney [9] of rat and the skeletal muscle of sheep [17]. The skeletal muscle composes about $40-50 \%$ of body mass and is the major site of glucose and fatty acid utilization, playing an important role in preventing obesity and type 2 diabetes (T2D) $[36,47]$. There is growing evidence that increased mitochondrial function may be essential for skeletal myogenesis [33]. Moreover, mitochondrial dysfunction in the skeletal muscle is been implicated in the development of T2D $[2,19]$. Studies in mice have shown that maternal exposure to a low-protein diet during pregnancy and lactation decreases mitochondrial DNA content and citrate synthase activity and leads to mitochondrial gene expression changes in the offspring liver and skeletal muscle $[18,27]$. However, currently, to our knowledge, no studies have addressed the effects of maternal low-energy (LE) diets on fetal offspring skeletal muscle mitochondrial biogenesis and function.

Compared with sheep and rodents, pigs share a number of anatomical and physiological similarities with humans making them an excellent experimental model for metabolic studies [31, 39]. However, there is no data in the pig skeletal muscle on how maternal LE intake during pregnancy may affect mitochondrial number and function. In addition, prenatal skeletal muscle development is particularly susceptible to environmental factors in mammalians [8]. Thus, understanding the effect of maternal LE diet on mitochondrial biogenesis and function in the skeletal muscle of the pig fetuses may provide important insights into the fetal origins of the metabolic syndrome. In the present study, our objective was to investigate the effects of moderately decreased maternal dietary energy intake during pregnancy on skeletal muscle mitochondrial biogenesis in pig fetuses on day 90 of pregnancy.

\section{Methods}

\section{Animals and diets}

The experimental procedures were approved by the Animal Care and Use Committee of Sichuan Agricultural University. Eight primiparous, purebred Meishan sows (initial body weight $72.8 \pm 4.0 \mathrm{~kg}$ ) were artificially inseminated three times, at the third observation of estrus, with the semen of purebred Meishan boars. The day of the last insemination constituted the first day of pregnancy. The pregnant sows were randomly assigned to one of the two experimental groups differing in daily digestible energy (DE) intake: standard-energy (SE) and low-energy (LE) groups. Based on the consideration that Meishan pigs, being raised with modern commercial diets composed following NRC standards, were traditionally raised on LE diets, we fed the sows in SE group with diets containing $12.90 \mathrm{MJ}$ of $\mathrm{DE} / \mathrm{kg}$, while those in $\mathrm{LE}$ group were fed diets containing $11.24 \mathrm{MJ}$ of $\mathrm{DE} / \mathrm{kg}$ to mimic the energy levels in traditional diets during pregnancy. During early pregnancy (days 1 to 35 of pregnancy), sows were fed with rations of $2.0 \mathrm{~kg} /$ day because lower feed intake level is beneficial to embryo survival during early pregnancy [16], supplying 25.80 and 22.48 MJ DE per day for SE and LE sows, respectively. Additionally, considering the rapid increasing demand of maternal weight gain and fetal growth during mid-late pregnancy (days 36 to 90 of pregnancy) [25], sows were fed on diets with the rations of $2.4 \mathrm{~kg} /$ day, supplying 30.96 and 26.98 MJ DE per day for SE and LE sows, respectively (Fig. 1). The isoprotein cornwheat bran-soybean meal-based diets were used, and the LE diet was formulated to allow the sow to ingest approximately $13 \%$ less DE than the SE group (Table 1 ). Although the additional dietary fiber was added to the LE diet to decrease energy concentration, crude fiber (CF) intake was only $1.52 \%$ higher in LE sows than in SE sows. Danielsen and Vestergaard [6] reported that even excess dietary fiber intake (CF, 4.6 vs $12.7 \%$ ) of pregnant sows influenced neither fetal survival nor litter size at birth. Consequently, it is quite unlikely in this experiment that the dietary fiber supplementation affected the fetal survival rate directly. The dietary treatments were introduced from mating to day 90 of pregnancy. During pregnancy, sows were housed in individual feed stalls in a breeding facility. Sows were fed discretely twice daily (08:00 and 14:00 h) with $50 \%$ of the daily ration each time and had free access to drinking water.

\section{Sample collection}

After a 12-h overnight fast, pregnant sows of both groups (SE/LE) were weighed and anesthetized with an intramuscular injection of Zoletil (Zoletil 50, Virbac; $4 \mathrm{mg} / \mathrm{kg}$ body weight) on day 90 of pregnancy $(n=4 / 4)$. The maternal abdomen was opened, and the reproductive tracts were removed immediately. Blood from the umbilical vein of each fetus was collected and coagulated for $30 \mathrm{~min}$ and then centrifuged at $3500 \times g$ for $10 \mathrm{~min}$ to separate serum which was stored at $-20{ }^{\circ} \mathrm{C}$ until analysis. The body weight of each fetus was recorded. Two female fetuses and two male fetuses, with weight close to the average level, were selected from each sow for muscle sample collection. The longissimus muscles (LMs) were collected from the fetuses, snap-frozen in liquid nitrogen, and stored at $-80^{\circ} \mathrm{C}$ until subsequent analysis.

\section{Measurement of metabolites and hormone}

The malondialdehyde (MDA) concentration in the skeletal muscle was measured using an assay kit (Jiancheng Institute of Bioengineering, Nanjing, Jiangsu, China). The concentrations of triglyceride and glucose in umbilical vein serum were determined using commercial kits 


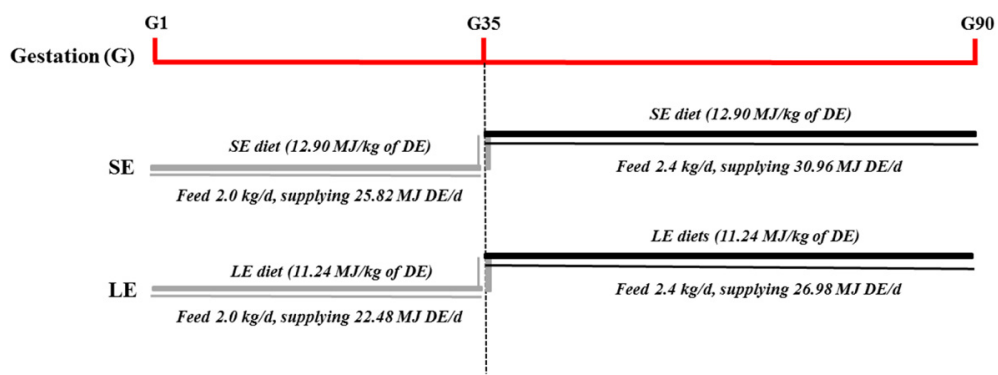

Fig. 1 The experimental design and the timing of the different treatments and procedures. SE maternal standard-energy diet, LE maternal low-energy diet, DE digestible energy

Table 1 Ingredients and composition of the experimental diets (as-fed basis)

\begin{tabular}{|c|c|c|}
\hline Items & SE & LE \\
\hline \multicolumn{3}{|l|}{ Ingredient (\%) } \\
\hline Maize & 45.00 & 45.00 \\
\hline Soybean meal & 13.60 & 13.60 \\
\hline Wheat bran & 27.80 & 27.80 \\
\hline Soybean oil & 4.50 & - \\
\hline Wheat bran fiber & 2.54 & 5.02 \\
\hline Soyabean fiber & 1.10 & 2.17 \\
\hline Corn fiber & 0.96 & 1.91 \\
\hline Salt & 0.40 & 0.40 \\
\hline L-Lys.HCl, 75 \% & 0.10 & 0.10 \\
\hline L-Thr & 0.10 & 0.10 \\
\hline Limestone & 1.23 & 1.23 \\
\hline Monocalcium phosphate & 1.99 & 1.99 \\
\hline Choline chloride, 50 \% & 0.14 & 0.14 \\
\hline$V_{i t a m i n}$ premix ${ }^{a}$ & 0.04 & 0.04 \\
\hline Mineral premix ${ }^{b}$ & 0.50 & 0.50 \\
\hline Total & 100.00 & 100.00 \\
\hline \multicolumn{3}{|l|}{ Nutritional composition } \\
\hline Digestible energy, MJ/kg & 12.90 & 11.24 \\
\hline Crude protein (\%) & 13.92 & 14.35 \\
\hline Crude fiber (\%) & 4.97 & 6.49 \\
\hline Lys (\%) & 0.69 & 0.69 \\
\hline Met + Cys (\%) & 0.35 & 0.35 \\
\hline $\operatorname{Thr}(\%)$ & 0.46 & 0.46 \\
\hline $\mathrm{Ca}(\%)$ & 0.96 & 0.96 \\
\hline Available P (\%) & 0.48 & 0.48 \\
\hline Total P (\%) & 0.79 & 0.79 \\
\hline
\end{tabular}

aprovided the following per kilogram of diet: $1.2 \mathrm{mg}$ retinol, $0.02 \mathrm{mg}$ cholecalciferol, $44 \mathrm{mg}$ a-tocopherol, $0.5 \mathrm{mg}$ phylloquinone, $1 \mathrm{mg}$ thiamin, $3.75 \mathrm{mg}$ riboflavin, $1 \mathrm{mg}$ pyridoxine, $0.015 \mathrm{mg}$ cyanocobalamin, $10 \mathrm{mg}$ niacin, $12 \mathrm{mg}$ pantothenic acid, $1.3 \mathrm{mg}$ folic acid, and $0.2 \mathrm{mg}$ biotin

${ }^{b}$ Provided the following per kilogram of diet: $80 \mathrm{mg} \mathrm{Fe}\left(\right.$ as $\mathrm{FeSO}_{4} .7 \mathrm{H}_{2} \mathrm{O}$ ), $10 \mathrm{mg}$ $\mathrm{Cu}$ (as CuSO ${ }_{4} \cdot 5 \mathrm{H}_{2} \mathrm{O}$ ), $100 \mathrm{mg} \mathrm{Zn} \mathrm{(as} \mathrm{ZnSO}_{4} \cdot 7 \mathrm{H}_{2} \mathrm{O}$ ), $25 \mathrm{mg} \mathrm{Mn}$ (as $\mathrm{MnSO}_{4} \cdot \mathrm{H}_{2} \mathrm{O}$ ), $0.15 \mathrm{mg} \mathrm{Se}$ (as $\mathrm{Na}_{2} \mathrm{SeO}_{3}$ ), and $0.14 \mathrm{mg} \mathrm{I}$ (as $\mathrm{KI}$ )
(Jiancheng Institute of Bioengineering, Nanjing, Jiangsu, China) according to the provided instructions. Growth hormone $(\mathrm{GH})$ concentration in umbilical vein serum was measured using a commercially available radioimmunoassay kits purchased from Beijing North Institute of Biotechnology (Beijing, China). Insulin was determined with porcine ELISA kit (R\&D Systems, Minneapolis, MN, USA). Sensitivities of the assays were $0.02 \mathrm{ng} / \mathrm{ml}$ and 2.15 $\mathrm{pmol} / \mathrm{l}$ for $\mathrm{GH}$ and insulin, respectively. Intra- and interassay coefficients of variation were 4.3 and $6.6 \%$ for $\mathrm{GH}$ and 3.9 and $7.4 \%$ for insulin, respectively.

\section{Measurement of enzyme activities}

The activities of superoxide dismutase (SOD), glutathione peroxidase (GPx), and catalase (CAT) in the skeletal muscle were measured using assay kits (Jiancheng Institute of Bioengineering, Nanjing, Jiangsu, China). Citrate synthase (CS) activity in the skeletal muscle was measured spectrophotometrically using a commercial kit (GenMed Scientifics Inc, USA).

\section{$\mathrm{NAD}^{+}$-to-NADH ratio measurement}

The $\mathrm{NAD}^{+}$-to-NADH ratio in the skeletal muscle was measured using a colorimetric assay kit (BioVision, Milpitas, CA, USA) according to the manufacturer's instructions. Briefly, muscle samples were washed with cold PBS followed homogenization using $\mathrm{NAD}^{+} / \mathrm{NADH}$ extraction buffer. To decompose $\mathrm{NAD}^{+}, 200 \mu \mathrm{l}$ of extract was heated to $60{ }^{\circ} \mathrm{C}$ for $30 \mathrm{~min}$. Under this condition, all $\mathrm{NAD}^{+}$were decomposed but keeping NADH intact. Both heated and unheated extract from each sample, together with the $\mathrm{NADH}$ standard solutions, were transferred into 96-well plates, added with $100 \mu \mathrm{l}$ of NAD cycling mix into each well, mixed, and incubated at room temperature for 5 min to convert $\mathrm{NAD}^{+}$to $\mathrm{NADH}$. Then, $10 \mu \mathrm{l}$ of NADH developer was added into each well and incubated at room temperature for $2 \mathrm{~h}$. Read the plate at OD $450 \mathrm{~nm}$. The amount of $\mathrm{NAD}^{+}$from each sample was calculated as total NAD (values from the unheated extracts) minus NADH (values from the heated extracts) and then divided by the protein concentration. 


\section{Mitochondrial DNA copy number}

Total DNA was extracted from LM muscle using QIAamp DNA extraction kit (QIAGEN, Valencia, CA, USA). The mitochondrial DNA (mtDNA) copy number was determined using quantitative real-time PCR as previously described with some modifications [5]. mtDNA was amplified using primers specific for the mitochondrial cytochrome $\mathrm{b}$ $(M T-C Y B)$ and normalized to genomic DNA by amplification of the $18 S$ rRNA. The sequence of primers was presented in Table 2 .

\section{Quantitative real-time PCR}

Total RNA was extracted from frozen muscle tissues using RNAiso Plus reagent (Takara, Dalian, China), and complementary DNA (cDNA) was synthesized from $0.5 \mu \mathrm{g}$ of the total RNA using the PrimeScript ${ }^{\text {tix }} \mathrm{RT}$ reagent kit (Takara). Real-time quantitative PCR was carried out in the final volume of $10 \mathrm{ul}$ containing $5 \mathrm{ul}$ of SYBR ${ }^{\circ}$ Premix Ex TaqTM II, $0.8 \mathrm{ul}$ of the primer pair, $0.2 \mathrm{ul}$ of ROX Reference Dye, $1 \mathrm{ul}$ of cDNA template, and $3 \mathrm{ul}$ of $\mathrm{dH}_{2} \mathrm{O}$

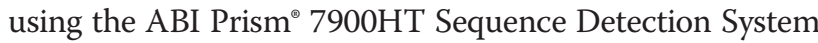
(Applied Biosystems, Foster city, CA, USA). The thermal cycling parameters comprised an initial denaturation step at $95{ }^{\circ} \mathrm{C}$ for $30 \mathrm{~s}, 40$ cycles of PCR reaction at $95{ }^{\circ} \mathrm{C}$ for $5 \mathrm{~s}$, and $60{ }^{\circ} \mathrm{C}$ for $34 \mathrm{~s}$, followed by a dissociation step at $95^{\circ} \mathrm{C}$ for $15 \mathrm{~s}, 60^{\circ} \mathrm{C}$ for $1 \mathrm{~min}$, and $95^{\circ} \mathrm{C}$ for $15 \mathrm{~s}$. To confirm specific product amplification, melt curve analysis was conducted. Primers for individual genes were designed using Primer Express 3.0 (Applied Biosystems) and are shown in Table 2. For normalization, ACTB was chosen as the reference gene since no variation in its expression was observed between treatments. The messenger RNA (mRNA) level of each target gene for SE group was set to 1.0.

Table 2 Primer sequences of the target and reference genes

\begin{tabular}{|c|c|c|c|}
\hline Gene & Primer sequence $\left(5^{\prime}-3^{\prime}\right)$ & Product size (bp) & GeneBank no. \\
\hline PPARGC1A & $\begin{array}{l}\text { F: CCCGAAACAGTAGCAGAGACAAG } \\
\text { R: CTGGGGTCAGAGGAAGAGATAAAG }\end{array}$ & 111 & NM_213963 \\
\hline SIRT1 & $\begin{array}{l}\text { F: TGACTGTGAAGCTGTACGAGGAG } \\
\text { R: TGGCTCTATGAAACTGCTCTGG }\end{array}$ & 143 & EU030283.2 \\
\hline NRF1 & $\begin{array}{l}\text { F: GCCAGTGAGATGAAGAGAAACG } \\
\text { R: CTACAGCAGGGACCAAAGTTCAC }\end{array}$ & 166 & AK237171.1 \\
\hline TFAM & $\begin{array}{l}\text { F: GGTCCATCACAGGTAAAGCTGAA } \\
\text { R: ATAAGATCGTITCGCCCAACTTC }\end{array}$ & 167 & NM_001130211 \\
\hline \multirow[t]{2}{*}{ ATP5B } & F: CATGAAGCAGGTGGCAGGTA & 127 & NM_001185142 \\
\hline & R: CAGACGAACACCACGACTCA & & \\
\hline \multirow[t]{2}{*}{ POLG } & F: CTTTGAGGTTTTCCAGCAGCAG & 119 & XM_005653521.1 \\
\hline & R: GCTCCCAGTTITGGTTGACAG & & \\
\hline \multirow[t]{2}{*}{ SSBP1 } & F: CTTTGAGGTAGTGCTGTGTCG & 142 & XM_005673118.1 \\
\hline & R: CTCACCCCTGACGATGAAGAC & & \\
\hline \multirow[t]{2}{*}{$\operatorname{COX} 4$} & F: CCAAGTGGGACTACGACAAGAAC & 131 & Liu et al. [22] \\
\hline & R: CCTGCTCGTTTATTAGCACTGG & & \\
\hline \multirow[t]{2}{*}{ CYCS } & F: TAGAAAAGGGAGGCAAACACAAG & 154 & Liu et al. [22] \\
\hline & R: GGATTCTCCAGGTACTCCATCAG & & \\
\hline \multirow[t]{2}{*}{ CS } & F: CCTITCAGACCCCTACTTGTCCT & 127 & Liu et al. [22] \\
\hline & R: CACATCTTTGCCGACTTCCTTC & & \\
\hline \multirow[t]{2}{*}{ CUZn-SOD } & F: AACATGGTGGGCCAAAGGAT & 136 & NM_001190422.1 \\
\hline & R: CGGCCAATGATGGAATGGTC & & \\
\hline \multirow[t]{2}{*}{ ACTB } & F: TCTGGCACCACACCTTCT & 114 & DQ178122 \\
\hline & R: TGATCTGGGTCATCTTCTCAC & & \\
\hline$M T-C Y B$ & $\begin{array}{l}\text { F: ATGAAACATTGGAGTAGTCCTACTATTTACC } \\
\text { R: CTACGAGGTCTGTTCCGATATAAGG }\end{array}$ & 149 & NC_000845.1 \\
\hline \multirow[t]{2}{*}{185 rRNA } & F: GGTAGTGACGAAAAATAACAATACAGGAC & 141 & NC_010448.3 \\
\hline & R: ATACGCTATTGGAGCTGGAATTACC & & \\
\hline
\end{tabular}

ACTB $\beta$-actin, COX cytochrome c oxidase, CS citrate synthase, CUZn-SOD copper/zinc superoxide peroxidase, MT-CYB mitochondrially encoded cytochrome b, CYCS cytochrome c, somatic, ATP5B $\beta$ subunit of mitochondrial $\mathrm{H}^{+}$-ATP synthase, NRF1 nuclear respiratory factor 1, PPARGC1A peroxisome proliferator-activated receptor gamma coactivator 1a, POLG gamma DNA polymerase, SIRT1 sirtuin 1, SSBP1 mitochondrial single-strand DNA-binding protein, TFAM mitochondrial transcription factor A 


\section{Immunoblotting analysis}

Total protein was extracted from frozen muscle tissue using the protein extraction kit (Beyotime Biotechnology, Jiangsu, China) according to the manufacturer's guide. The protein content of lysates was measured with the Pierce BCA protein Assay kit (Thermo, Waltham, MA, USA). Immunoblotting analysis was performed as previously described [29]. The primary antibodies included PPARGC1A (ab54481, Abcam, Cambridge, MA, USA), Sirt1 (sc-19857, Santa Cruz Biotechnology, CA, USA), CuZn-SOD (sc-271014, Santa Cruz Biotechnology), and $\beta$-tubulin (sc-9104, Santa Cruz Biotechnology). The density of bands was quantified using the Gel Doc XR System (Bio-Rad, Hercules, CA, USA) and then normalized to $\beta$-tubulin content. The normalized values were used for comparison of the expression of target protein between SE and LE groups.

\section{Statistical analysis}

Results were presented as least square means with their standard errors. Data were analyzed using the MIXED procedures of Statistical Analysis System (version 8.1, SAS Institute, Inc.) with treatment, gender, and the twoway interactions as the fixed effect and with sow as the random effect. However, none of the gender and interactions were statistically significant. Therefore, they were removed from the model, and data from female and male fetuses were pooled together for analysis. The least square means were separated using the PDIFF option with the Turkey adjustment. The $2^{-\Delta \Delta \mathrm{Ct}}$ method was used to analyze the relative changes in each gene expression [23]. Statistical significance was considered as $P<0.05$, and a tendency towards difference was considered as $P<0.10$.

\section{Results}

\section{Pregnancy performance}

On day 90 of pregnancy, the maternal body weight and fetal weight were reduced in LE group $(P<0.05$; Table 3$)$. However, no significant differences were observed for litter size and variation in fetal weight within a litter (as indicated by the coefficient of variation) between SE and LE groups $(P>0.05)$.

\section{Serum concentrations of metabolites and hormone}

As shown in Table 4, the glucose concentration tended to be reduced $(P=0.091)$ in umbilical vein serum of LE fetuses. Serum GH concentration was significantly decreased $(P<0.05)$ in LE fetuses compared with SE group, whereas maternal diet had no effect on the concentrations of triglyceride and insulin $(P>0.05)$.
Table 3 Sow body weight, litter size, fetal weight, and variation in fetal weight within a litter on day 90 of pregnancy

\begin{tabular}{lllll}
\hline Item & SE & LE & SEM & $P$ value \\
\hline Sow BW (kg) & & & & \\
$\quad$ At insemination & 72.7 & 72.9 & 0.9 & 0.840 \\
$\quad$ At day 90 of pregnancy & 127.9 & 117.0 & 1.9 & 0.002 \\
Litter size & 12.0 & 11.8 & 0.9 & 0.856 \\
Fetal weight (g) & 574.4 & 507.7 & 17.9 & 0.039 \\
CV, \% & 14.86 & 12.72 & 1.48 & 0.345
\end{tabular}

$n=4$ for each group

SE maternal standard-energy diet, $L E$ maternal low-energy diet, $B W$ body weight, $C V$ coefficient of variation, values determined from fetal weights within each litter

Mitochondrial DNA contents, CS activity, and the NAD+-toNADH ratio

As shown in Fig. 2a, the mtDNA copy number in the skeletal muscle was significantly lower $(P<0.05)$ in LE fetuses than in SE fetuses. Furthermore, CS activity was also reduced $(P<0.05)$ in LE fetuses (Fig. 2b). Though $\mathrm{NADH}$ level was not changed $(P>0.05)$, the $\mathrm{NAD}^{+}$level and $\mathrm{NAD}^{+}$-to-NADH ratio were significantly decreased $(P<0.05)$ in the skeletal muscle of LE fetuses compared with SE fetuses (Fig. 2c).

\section{Expression of genes implicated in mitochondrial biogenesis and function}

To clarify the mechanisms involved in the reduction of mitochondrial density in the muscle of LE fetuses, we measured the expression of genes implicated in mitochondrial biogenesis and function. As shown in Fig. 3a, b, the mRNA and protein levels of PPARGC1A and Sirt1 in LE fetuses were decreased $(P<0.05)$ when compared with SE group. In addition, the mRNA abundance of nuclear respiratory factor 1 (NRF1), mitochondrial transcription factor A (TFAM), $\beta$ subunit of mitochondrial $\mathrm{H}^{+}$-ATP synthase (ATP5B), and CS were significantly decreased in the skeletal muscle of LE fetuses as well $(P<0.05$, Fig. 3c). Meanwhile, the mRNA abundance of gamma DNA polymerase (POLG) and single-stranded DNA-binding protein 1 (SSBP1) responsible for mtDNA replication were lower $(P<0.05$, Fig. $3 \mathrm{~d})$ in LE fetuses.

Table 4 Concentrations of metabolites and hormones in fetal umbilical vein serum on day 90 of pregnancy

\begin{tabular}{lrrrc}
\hline Item & \multicolumn{1}{l}{ SE } & \multicolumn{1}{l}{ LE } & SEM & $P$ value \\
\hline Glucose $(\mathrm{mmol} / \mathrm{l})$ & 4.07 & 3.55 & 0.19 & 0.091 \\
Triglyceride $(\mathrm{mmol} / \mathrm{l})$ & 0.30 & 0.26 & 0.02 & 0.275 \\
GH $(\mathrm{ng} / \mathrm{ml})$ & 20.06 & 17.57 & 0.72 & 0.021 \\
Insulin $(\mathrm{pmol} / \mathrm{ml})$ & 134.98 & 130.16 & 2.80 & 0.227 \\
\hline
\end{tabular}

$n=16$ for each group

$S E$ maternal standard-energy diet, LE maternal low-energy diet, GH growth hormone 
$\mathbf{a}$

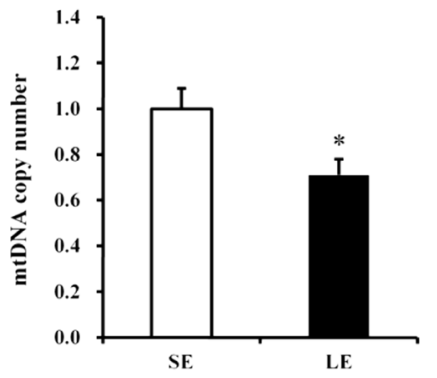

b

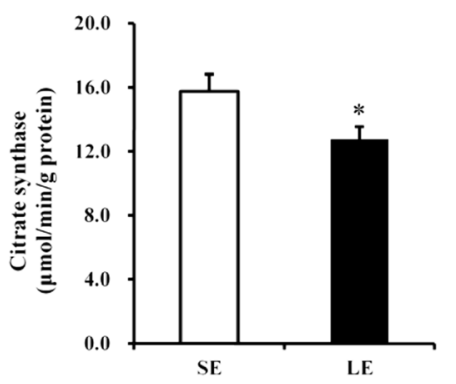

c
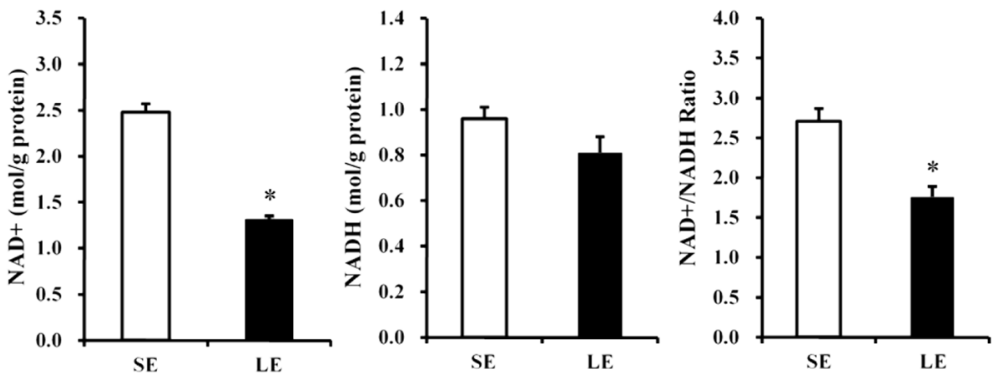

Fig. 2 mtDNA copy number (a), citrate synthase activity (b), and the NAD+-to-NADH ratio (c) in the fetal longissimus muscles of SE and LE sows. Values are least squares means $\pm S E M s, n=16$. SE maternal standard-energy diet, LE maternal low-energy diet, $m t D N A$ mitochondrial DNA. * $P<0.05$ compared with SE group

MDA level, CuZn-SOD gene expression, and antioxidant enzyme activities in the skeletal muscle

We further measured the MDA level, CuZn-SOD expression, and the activities of three major antioxidative enzymes in the skeletal muscle to determine the effects of maternal energy restriction on reactive oxygen species (ROS) defense system. As shown in Table 5 and Fig. 4, the LE fetuses had markedly lower activities of SOD and CAT $(P<0.05)$ and mRNA and protein expression of CuZn-SOD $(P<0.05)$ in the skeletal muscle compared to the SE fetuses. No significant changes in MDA level and GPx activity were found between treatments $(P>0.05)$.

\section{Discussion}

Epidemiological data demonstrate that low birth weight due to maternal malnutrition is associated with increased rates of metabolic diseases in adulthood $[1,11]$. This study used the domestic pig as an animal model for the study of maternal nutrition and is of interest for human health and livestock science. Consistent with previous reports $[15,32]$, the maternal LE diets decreased fetal weight, which was linked to significantly lower serum GH concentration. Cumulative evidence have shown that mitochondrial dysfunction in the skeletal muscle is implicated in the developmental origins of metabolic syndrome [3, 43]. Mitochondria are inherited through the maternal lineage and easily affected by the environment because of its position outside the nucleus [37]. It was reported that maternal low-protein diets during gestation affect mtDNA transcription regulation through changing the DNA methylation and hydroxymethylation on the promoter of mtDNA in the liver of newborn piglets [15]. Previous studies in rodents also suggest that maternal nutritional stress causes changes to skeletal muscle mitochondrial function and oxidative metabolism that persist into adult offspring, increasing the risk of T2D [4, 21]. Moreover, because mitochondrial biogenesis accompanies skeletal myogenesis [34], and we previously reported that maternal LE diets attenuate fetal skeletal muscle development [48], thus, we hypothesized that the impairment of mitochondrial biogenesis may contribute to maternal LE diet-induced delayed skeletal myogenesis in pig fetuses. In the present study, we found that maternal LE diets during pregnancy decreased the mtDNA copy number in the skeletal muscle of LE fetuses, indicating a decrease in mitochondrial density. Similar results have been reported previously in rats' offspring of dams fed with a lowprotein diet $[30,41]$. However, some studies have shown no consistent effects, and even advantageous effects, on mtDNA copy number when prenatal exposure to maternal low-protein diets in various tissues of different animal models, including the muscle in sheep [17] and muscle [4] and kidney [9] in rats, as well as fat in mice [18]. Thus, there are contradictory results on how maternal nutritional limitation during pregnancy affects mitochondrial biogenesis in the offspring. These findings imply that the time period and duration of treatment during pregnancy, the type and amount of nutrient changes, and the different 


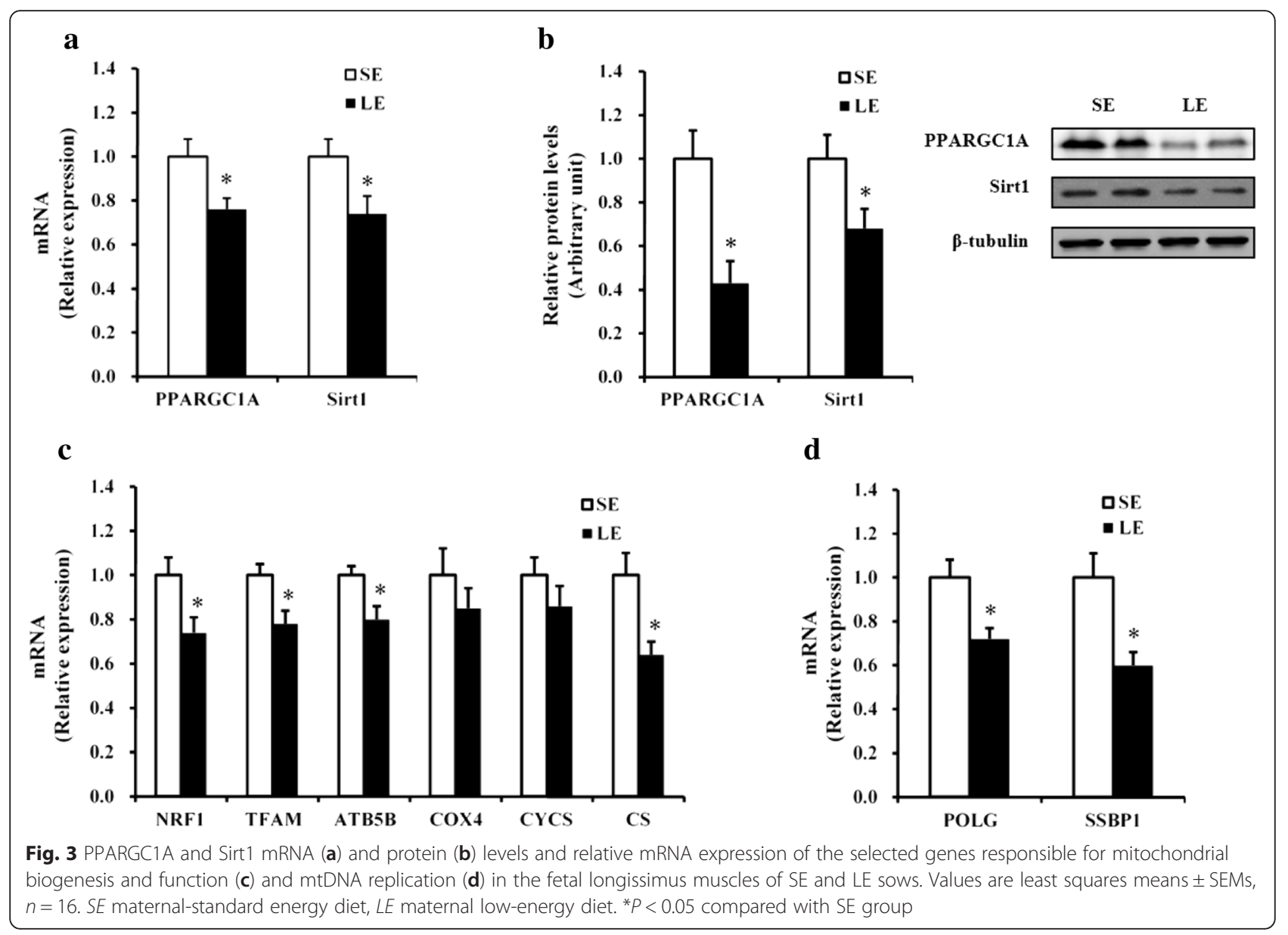

animal models and tissues tested seem to be important factors resulting in variation between studies. To our knowledge, this is the first report regarding the effect of maternal LE diets on mtDNA content in the skeletal muscle of pig fetuses.

The decrease in muscle mtDNA content indicates disrupted mitochondrial biogenesis. The control of mitochondrial biogenesis is a complex biological process that needs the coordinated regulation of multiple transcriptional factors, including nuclear and mitochondrial-encoded genes [10]. It is well established that the $\mathrm{NAD}^{+}$-dependent

Table 5 Malondialdehyde content and antioxidant enzyme activities in the fetal longissimus muscle of SE and LE sows

\begin{tabular}{lllll}
\hline Item & SE & LE & SEM & $P$ value \\
\hline MDA (nmol/mg protein) & 2.18 & 2.05 & 0.13 & 0.468 \\
SOD (U/mg protein) & 32.39 & 28.59 & 0.51 & 0.008 \\
GPX (U/mg protein) & 40.32 & 36.17 & 2.05 & 0.169 \\
CAT (U/mg protein) & 8.35 & 6.41 & 0.45 & 0.006
\end{tabular}

$n=16$ for each group

$S E$ maternal standard energy diet, $L E$ maternal low energy diet, MDA malondialdehyde, $S O D$ superoxide dismutase, GPx glutathione peroxidase, CAT catalase deacetylase Sirt1 plays an important role in numerous fundamental cellular processes including gene silencing, DNA repair, and metabolic regulation [14]. In our study, the expression of Sirt1 at both the mRNA and protein levels was reduced in the skeletal muscle of LE fetuses. Because Sirt1 deacetylase activity is driven by $\mathrm{NAD}^{+}$levels, we examined whether maternal LE diets suppress Sirt1 by altering the intracellular $\mathrm{NAD}^{+} / \mathrm{NADH}$ ratio. Supporting this hypothesis, the $\mathrm{NAD}^{+} / \mathrm{NADH}$ ratio was decreased in LE fetuses. However, NADH content was not changed by maternal LE diets, implying that, apart from the interconversion of $\mathrm{NAD}^{+}$and NADH during redox reactions, the concentration of both partners of this redox pair may be controlled by other mechanisms as well. Previous study in astrocytes has shown that both $\mathrm{NAD}^{+}$and NADH contents are controlled independently from each other [44]. Sirt1 deacetylates and activates PPARGC1A $[10,13]$, the master regulator of mitochondrial biogenesis that coactivates the NRF-1, which induce the expression of genes involved in mitochondrial biogenesis [46]. In the present study, we found that the mRNA and protein expression of PPARGC1A were reduced in the skeletal muscle of LE fetuses. Consistently, the mRNA 


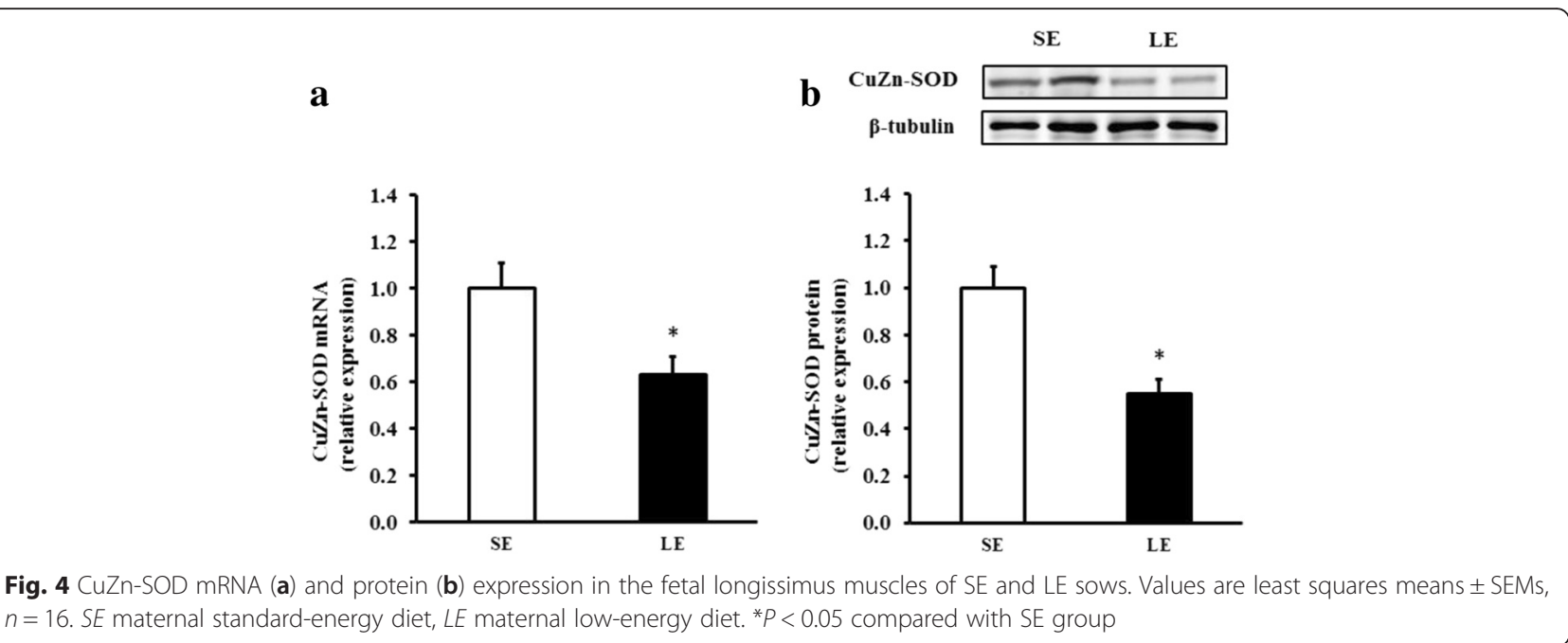

expression of NRF1 were decreased in LE fetuses. With further investigation, the mRNA expression of TFAM, a direct regulator of mtDNA replication and transcription that could be regulated by PPARGC1A and NRF1 [46], was reduced in LE fetuses as well. Similar with previous reports in rats [30,41], abnormal expression patterns of genes implicated in mtDNA biogenesis in the offspring liver or pancreatic islets of malnourished dams were observed. Additionally, because ATP5B is a critical molecule required for mitochondrial ATP synthesis [7], the decrease of mitochondrial biogenesis in LE fetuses was also reflected by down-regulated expression of ATP5B. Gamma DNA polymerase (POLG) and SSBP1 play a key role in mtDNA replication and repair [35]. As expected, we observed a decrease in POLG and SSBP1 in the skeletal muscle of LE fetuses. Together, these data show that maternal LE diets significantly reduced intracellular $\mathrm{NAD}^{+}$levels and as a result decreased Sirt1 expression that subsequently decreased mtDNA replication and mitochondrial biogenesis in the skeletal muscle of LE fetuses.

Maternal malnutrition is associated with a depressed mitochondrial function and respiration in offspring $[4,9,17]$. In this study, although the mRNA expression levels of genes, such as COX4 and CYCS, responsible for mitochondrial function were not changed in LE fetuses, CS mRNA expression and activity were markedly decreased. Because it has been suggested a role for oxidative stress in skeletal muscle mitochondrial dysfunction [2], we speculate that oxidative stress may be implicated in undernutrition-associated mitochondrial alterations. ROS removal is regulated by many antioxidant enzymes, including SOD, GPx, and CAT [24]. In the present study, the mRNA and protein expression of CuZn-SOD and activities of SOD and CAT were reduced in the skeletal muscle of LE fetuses, suggesting the failure of ROS defense system, which is also an evidence of mitochondrial function changes [28]. However, muscle GPx activity was not changed by maternal LE diets. Thus, changes in the antioxidant system seem to occur in an enzyme-specific manner in prenatal energy-restricted fetal pigs. Similarly, previous study showed that maternal protein malnutrition significantly reduced SOD activity while GPx activity was not significantly affected in the liver of rat offspring [30]. Therefore, the enhanced oxidative stress may not explain completely the mitochondrial changes in the fetal muscle as a whole. Previous studies have shown that acute $\mathrm{GH}$ action promotes muscle mitochondrial function by stimulating mitochondrial oxidative capacity and transcript abundance of mitochondrial genes [38]. It is here shown

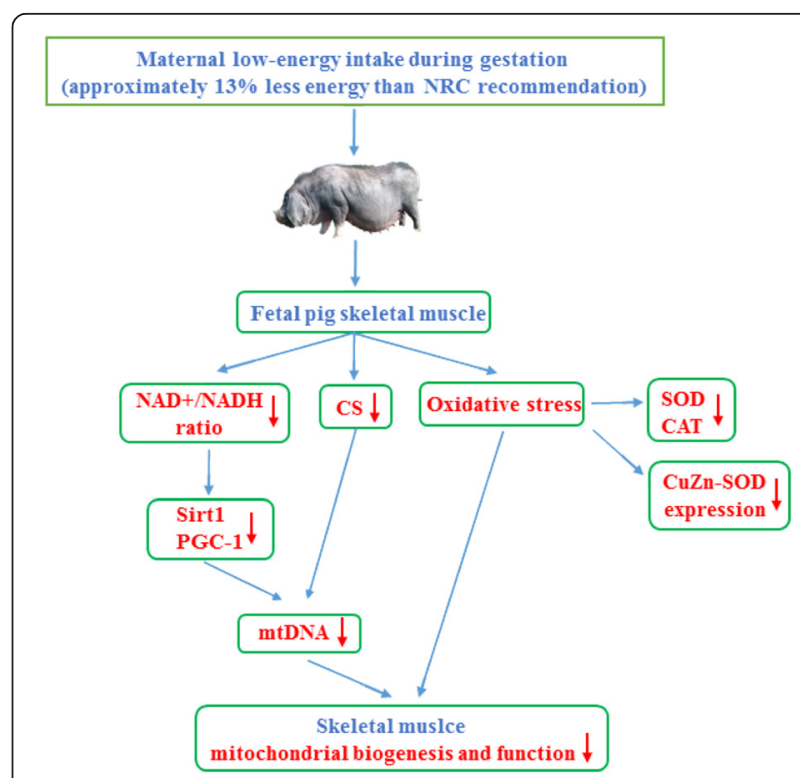

Fig. 5 Diagram explains the effect of moderately decreased maternal energy intake during gestation on skeletal muscle mitochondrial biogenesis and function in fetal pigs 
that $\mathrm{GH}$ concentrations in umbilical vein serum of $\mathrm{LE}$ fetuses were reduced, which could, at least partly, explain the decreases in skeletal muscle mitochondrial biogenesis and function.

\section{Conclusions}

This study provides evidence that moderately decreased maternal dietary energy intake in pregnant sows during pregnancy impairs fetal development on day 90 of pregnancy, through decreased mitochondrial biogenesis and function in the skeletal muscle (Fig. 5). The mitochondrial changes during fetal life may further contribute to the disorder of energy homeostasis in adulthood. Consequently, understanding the molecular mechanisms underlying the effect of maternal undernutrition on fetal development may give access to useful knowledge regarding the onset of metabolic diseases.

\section{Acknowledgements}

This study was supported by the National Basic Research Program of China (2012CB124701) and the National Natural Science Foundation of China (31372323).

\section{Authors' contributions}

$T Z, B Y, J Y, X M, P Z, J H$, and ZH participated in the design of the study and performed the statistical analysis. DC conceived and designed the study and helped in drafting the manuscript. TZ and YL carried out the animal experiments and performed the laboratory work. TZ wrote the manuscript. All authors read and approved the final manuscript.

\section{Competing interests}

The authors declare that they have no competing interests.

\section{Ethics approval and consent to participate}

All institutional and national guidelines for the care and use of laboratory animals were followed. The experimental procedures were approved by the Animal Care and Use Committee of Sichuan Agricultural University.

\section{Received: 24 February 2016 Accepted: 15 June 2016}

Published online: 23 June 2016

\section{References}

1. Barker D. The developmental origins of adult disease. J Am Coll Nutr. 2004;23:588S-95.

2. Bonnard C, Durand A, Peyrol S, Chanseaume E, Chauvin M-A, Morio B, et al. Mitochondrial dysfunction results from oxidative stress in the skeletal muscle of diet-induced insulin-resistant mice. J Clin Invest. 2008;118:789-800.

3. Bruce KD, Hanson MA. The developmental origins, mechanisms, and implications of metabolic syndrome. J Nutr. 2010;140:648-52.

4. Claycombe KJ, Roemmich JN, Johnson L, Vomhof-DeKrey EE, Johnson WT. Skeletal muscle Sirt3 expression and mitochondrial respiration are regulated by a prenatal low-protein diet. J Nutr Biochem. 2015;26:184-9.

5. D'Antona G, Ragni M, Cardile A, Tedesco L, Dossena M, Bruttini F, et al. Branched-chain amino acid supplementation promotes survival and supports cardiac and skeletal muscle mitochondrial biogenesis in middle-aged mice. Cell Metab. 2010;12:362-72.

6. Danielsen V, Vestergaard E-M. Dietary fibre for pregnant sows: effect on performance and behaviour. Anim Feed Sci Tech. 2001:90:71-80.

7. de Heredia ML, Izquierdo JM, Cuezva JM. A conserved mechanism for controlling the translation of $\beta$-F1-ATPase mRNA between the fetal liver and cancer cells. J Biol Chem. 2000:275:7430-7.

8. Du M, Yan X, Tong JF, Zhao J, Zhu MJ. Maternal obesity, inflammation, and fetal skeletal muscle development. Biol Reprod. 2010;82:4-12.

9. Engeham S, Mdaki K, Jewell K, Austin R, Lehner AN, Langley-Evans SC. Mitochondrial respiration is decreased in rat kidney following fetal exposure to a maternal low-protein diet. J Nutr Metab. 2012;2012:989037.
10. Fernandez-Marcos PJ, Auwerx J. Regulation of PGC-1a, a nodal regulator of mitochondrial biogenesis. Am J Clin Nutr. 2011:93:884S-90.

11. Fernandez-Twinn D, Ozanne S. Mechanisms by which poor early growth programs type-2 diabetes, obesity and the metabolic syndrome. Physiol Behav. 2006:88:234-43.

12. Garcia A, Palou M, Priego T, Sanchez J, Palou A, Pico C. Moderate caloric restriction during gestation results in lower arcuate nucleus NPY-and aMSH-neurons and impairs hypothalamic response to fed/fasting conditions in weaned rats. Diabetes Obes Metab. 2010;12:403-13.

13. Gerhart-Hines Z, Rodgers JT, Bare O, Lerin C, Kim SH, Mostoslavsky R, et al. Metabolic control of muscle mitochondrial function and fatty acid oxidation through SIRT1/PGC-1a. EMBO J. 2007;26:1913-23.

14. Haigis MC, Guarente LP. Mammalian sirtuins_emerging roles in physiology, aging, and calorie restriction. Genes Dev. 2006;20:2913-21.

15. Jia $Y$, Li R, Cong $R$, Yang $X$, Sun $Q$, Parvizi N, et al. Maternal low-protein diet affects epigenetic regulation of hepatic mitochondrial DNA transcription in a sex-specific manner in newborn piglets associated with GR binding to its promoter. PloS one. 2013;8:e63855.

16. Jindal $R$, Cosgrove J, Aherne F, Foxcroft $G$. Effect of nutrition on embryonal mortality in gilts: association with progesterone. J Anim Sci. 1996;74:620-4.

17. Jørgensen W, Gam C, Andersen JL, Schjerling P, Scheibye-Knudsen M, Mortensen $\mathrm{OH}$, et al. Changed mitochondrial function by pre-and/or postpartum diet alterations in sheep. Am J Physio-Endoc Metab. 2009:297:E1349-57.

18. Jousse C, Muranishi Y, Parry L, Montaurier C, Even P, Launay J-M, et al. Perinatal protein malnutrition affects mitochondrial function in adult and results in a resistance to high fat diet-induced obesity. Plos one. 2014;9:e104896.

19. Kelley DE, He J, Menshikova EV, Ritov VB. Dysfunction of mitochondria in human skeletal muscle in type 2 diabetes. Diabetes. 2002;51:2944-50.

20. King JC. Maternal obesity, metabolism, and pregnancy outcomes. Annu Rev Nutr. 2006;26:271-91.

21. Latouche C, Heywood SE, Henry SL, Ziemann M, Lazarus R, El-Osta A, et al. Maternal overnutrition programs changes in the expression of skeletal muscle genes that are associated with insulin resistance and defects of oxidative phosphorylation in adult male rat offspring. J Nutr. 2014;144:237-44.

22. Liu J, Chen D, Yao Y, Yu B, Mao X, He J, et al. Intrauterine growth retardation increases the susceptibility of pigs to high-fat diet-induced mitochondrial dysfunction in skeletal muscle. PloS one. 2012;7:e34835.

23. Livak KJ, Schmittgen TD. Analysis of relative gene expression data using real-time quantitative PCR and the $2^{-\Delta \Delta C T}$ method. Methods. 2001;25:402-8.

24. Mates J. Effects of antioxidant enzymes in the molecular control of reactive oxygen species toxicology. Toxicology. 2000;153:83-104.

25. McPherson R, Ji F, Wu G, Blanton J, Kim S. Growth and compositional changes of fetal tissues in pigs. J Anim Sci. 2004;82:2534-40.

26. Mitchell M, Schulz SL, Armstrong DT, Lane M. Metabolic and mitochondrial dysfunction in early mouse embryos following maternal dietary protein intervention. Biol Reprod. 2009:80:622-30.

27. Mortensen $\mathrm{OH}$, Olsen HL, Frandsen L, Nielsen PE, Nielsen FC, Grunnet N, et al. A maternal low protein diet has pronounced effects on mitochondrial gene expression in offspring liver and skeletal muscle; protective effect of taurine. J Biomed Sci. 2010;17:S38.

28. Murphy MP. Mitochondrial dysfunction indirectly elevates ROS production by the endoplasmic reticulum. Cell Metab. 2013;18:145-6.

29. Pang W, Wang Y, Wei N, Xu R, Xiong Y, Wang P, et al. Sirt1 inhibits akt2mediated porcine adipogenesis potentially by direct protein-protein interaction. PloS one. 2013;8:e71576.

30. Park KS, Kim SK, Kim MS, Cho EY, Lee JH, Lee K-U, et al. Fetal and early postnatal protein malnutrition cause long-term changes in rat liver and muscle mitochondria. J Nutr. 2003;133:3085-90.

31. Patterson JK, Lei XG, Miller DD. The pig as an experimental model for elucidating the mechanisms governing dietary influence on mineral absorption. Exp Biol Med. 2008:233:651-64.

32. Pond WG, Maurer RR, Klindt J. Fetal organ response to maternal protein deprivation during pregnancy in swine. J Nutr. 1991;121:504-9.

33. Remels A, Langen R, Schrauwen P, Schaart G, Schols A, Gosker H. Regulation of mitochondrial biogenesis during myogenesis. Mol Cell Endocrinol. 2010;315:113-20.

34. Rochard P, Rodier A, Casas F, Cassar-Malek I, Marchal-Victorion S, Daury L, et al. Mitochondrial activity is involved in the regulation of myoblast differentiation through myogenin expression and activity of myogenic factors. J Biol Chem. 2000;275:2733-44 
35. Scarpulla RC. Nuclear control of respiratory gene expression in mammalian cells. J Cell Biochem. 2006;97:673-83.

36. Schenk S, Horowitz JF. Acute exercise increases triglyceride synthesis in skeletal muscle and prevents fatty acid-induced insulin resistance. J Clin Invest. 2007;117:1690-8.

37. Schwartz M, Vissing J. New patterns of inheritance in mitochondrial disease. Biochem Bioph Res Co. 2003;310:247-51.

38. Short KR, Moller N, Bigelow ML, Coenen-Schimke J, Nair KS. Enhancement of muscle mitochondrial function by growth hormone. J Clin Endocr Metab. 2008:93:597-604.

39. Spurlock ME, Gabler NK. The development of porcine models of obesity and the metabolic syndrome. J Nutr. 2008;138:397-402.

40. Starkov AA. The role of mitochondria in reactive oxygen species metabolism and signaling. Ann NY Acad Sci. 2008;1 147:37-52.

41. Theys N, Bouckenooghe T, Ahn M-T, Remacle C, Reusens B. Maternal low-protein diet alters pancreatic islet mitochondrial function in a sex-specific manner in the adult rat. Am J Physiol Regul Integr Comp Physiol. 2009;297:R1516-25.

42. Thompson NM, Norman AM, Donkin SS, Shankar RR, Vickers MH, Miles JL, et al. Prenatal and postnatal pathways to obesity: different underlying mechanisms, different metabolic outcomes. Endocrinology. 2007;148:2345-54.

43. Wells GD, Noseworthy MD, Hamilton J, Tarnopolski M, Tein I. Skeletal muscle metabolic dysfunction in obesity and metabolic syndrome. Can J Neurol Sci. 2008:35:31-40

44. Wilhelm F, Hirrlinger J. The NAD+/NADH redox state in astrocytes: independent control of the NAD+ and NADH content. J Neurosci Res. 2011:89:1956-64.

45. Wu G, Bazer FW, Cudd TA, Meininger CJ, Spencer TE. Maternal nutrition and fetal development. J Nutr. 2004;134:2169-72.

46. Wu Z, Puigserver P, Andersson U, Zhang C, Adelmant G, Mootha V, et al. Mechanisms controlling mitochondrial biogenesis and respiration through the thermogenic coactivator PGC-1. Cell. 1999;98:115-24.

47. Youn JY, Cai H. Fueling up skeletal muscle to reduce obesity: a TrkB story. Chem Biol. 2015:22:311-2.

48. Zou T, He D, Yu B, Yu J, Mao X, Zheng P, et al. Moderate maternal energy restriction during gestation in pigs attenuates fetal skeletal muscle development through changing myogenic gene expression and myofiber characteristics. Reprod Sci. 2016. doi:10.1177/1933719116651151.

\section{Submit your next manuscript to BioMed Central and we will help you at every step:}

- We accept pre-submission inquiries

- Our selector tool helps you to find the most relevant journal

- We provide round the clock customer support

- Convenient online submission

- Thorough peer review

- Inclusion in PubMed and all major indexing services

- Maximum visibility for your research

Submit your manuscript at www.biomedcentral.com/submit

) Biomed Central 